\title{
Potential of Nanocellulose Composite for Electromagnetic Shielding
}

\author{
Nurul Fatihah Nabila Yah ${ }^{1}$, H.A.Rahim ${ }^{1, *}$, Yeng Seng Lee ${ }^{2}$, Wee Fwen Hoon ${ }^{1}$, Mohd Fareq Malek ${ }^{3}$, \\ Nik Adilah Hanin Zahri ${ }^{1}$, and Hayati Hasibuan Zainal ${ }^{1}$ \\ ${ }^{1}$ Bioelectromagnetic Research Group (BioEM), School of Computer and Communication Engineering, Universiti Malaysia Perlis, \\ Kampus Pauh Putra, 02600, Arau, Perlis, Malaysia \\ ${ }^{2}$ Faculty of Technology Engineering, Universiti Malaysia Perlis, Sg. Chuchuh Campus, Padang Besar, Perlis, Malaysia \\ ${ }^{3}$ Faculty of Engineering and Information Sciences, University of Wollongong in Dubai, Dubai, United Arab Emirates
}

\begin{abstract}
Nowadays, most people rely on the electronic devices for work, communicating with friends and family, school and personal enjoyment. As a result, more new equipment or devices operates in higher frequency were rapidly developed to accommodate the consumers need. However, the demand of using wireless technology and higher frequency in new devices also brings the need to shield the unwanted electromagnetic signals from those devices for both proper operation and human health concerns. This paper highlights the potential of nanocellulose for electromagnetic shielding using the organic environmental nanocellulose composite materials. In addition, the theory of electromagnetic shielding and recent development of green and organic material in electromagnetic shielding application has also been reviewed in this paper. The use of the natural fibers which is nanocelllose instead of traditional reinforcement materials provides several advantages including the natural fibers are renewable, abundant and low cost. Furthermore, added with other advantages such as lightweight and high electromagnetic shielding ability, nanocellulose has a great potential as an alternative material for electromagnetic shielding application.
\end{abstract}

\section{Introduction}

Recent years have shown a remarkable progress in development of wireless technology worldwide. In particular, technology that aims for higher frequency and wider bandwidth for establishing a high-speed communication system were rapidly developed to accommodate consumer need. However, all of these systems result in an increasing electromagnetic pollution or electromagnetic interference (EMI) to the surrounding. It has become a major concern which brings the need to shield the unwanted electromagnetic signals for both proper operation and human health.

Electromagnetic interference (EMI) can be defined as conducted or radiated electromagnetic signal that interferes with the operation of other electronic devices ${ }^{1}$. It can cause malfunction of the devices and even can be harmful to life ${ }^{2}$. To address this problem, studies on good materials for electromagnetic interference shielding is necessary. Electromagnetic interference shielding refers to the reflection and/or absorption of electromagnetic radiation by a material ${ }^{3}$.

Due to these circumstances, researches on the new and better materials for electromagnetic interference shielding have gained attention. Metals such as aluminium, copper and steel in forms like sheet metal, metal screen and metal foam are the most widely used materials for EMI shielding 2. But, there are several limitations in the applicability of metals in shielding application since they are heavy, not easily handled and they suffer from corrosion. Therefore in the last few years researchers have focused their interest in developing new shielding materials.

The present paper reviews the potential of nanocellulose material in electromagnetic shielding application. The second part of the paper discusses the theory and mechanism of electromagnetic shielding. The third part covers the recent development in researches on green and organic material as alternative material in electromagnetic application. Next the fourth part encompasses nanocellulose composites, its application and potential in electromagnetic shielding field. Lastly the challenges and potential of this research is concluded.

\footnotetext{
* Corresponding author: haslizarahim@unimap.edu.my
} 


\section{Theory of Shielding}

Three mechanisms of shielding have been reported which are absorption, reflection and multiple-reflection. For the EMI shielding by reflection, the material must have mobile charge carriers which interact with the electromagnetic wave ${ }^{43}$. Meanwhile, absorption is depends on the thickness of the materials. Shielding by absorption is significant when the shield have electric or magnetic dipoles. The third shielding which is multiplereflection refers to internal reflection within the shielding materials. The loss due to multiple-reflection can be ignored if the shield is thicker than skin depth.

Figure 1 shows the electromagnetic wave attenuation through a shielding material with different mechanism of shielding.

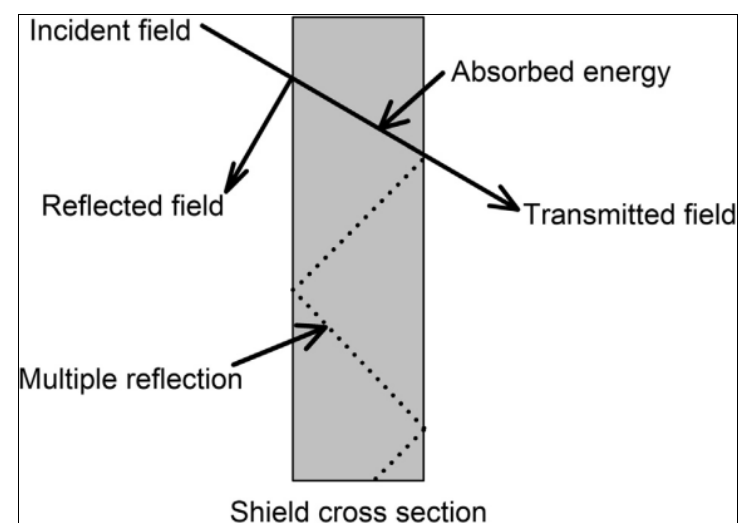

Fig. 1, Electromagnetic wave attenuation through a shielding material $^{5}$

Electromagnetic shielding effectiveness (EMI SE) of a material is the ratio of transmitted power $\left(P_{t}\right)$ to incident power $\left(P_{i}\right)$, expressed in decibels $(d B)$ as in Eq. (1): ${ }^{5}$

$$
S E_{\text {total }}(d B)=-10 \log \left(P_{t} / P_{i}\right)
$$

When an electromagnetic wave reaches a shielding material, two waves will be created at the external surface; a reflected wave $\left(E_{R}\right)$ and a transmitted wave $\left(E_{l-R}\right)$. As the transmitted wave travels through the shield, the strength of the wave exponentially decreases due to absorption. Once the wave reaches the second surface, a portion of the wave will be transmitted $\left(E_{T}\right)$ and a portion will be reflected into the shield $\left(E_{M R}\right)$. If the shield is thicker than the skin depth the reflected wave will be absorbed by the shielding material, thus can be ignored. The contribution of reflection, absorption and multiple-reflection to the total shielding effectiveness is defined in Eq. (2) : ${ }^{4-6}$

$$
S E_{\text {total }}(d B)=S E_{R}+S E_{A}+S E_{M R}
$$

Using S parameter, the transmittance $(\mathrm{T})$, reflectance (R), and absorbance (A) through the shielding material is obtained; $\mathrm{T}=S^{2}{ }_{12}=S_{21}^{2}, \mathrm{R}=S^{2}{ }_{11}=S^{2}{ }_{22}, \mathrm{~A}=1-\mathrm{R}$ - T. If multiple-reflection is ignored, the effective absorbance $\left(A_{e f f}\right)$ inside the shielding material can be defined as;

$$
A_{e f f}=(1-R-T) /(1-R)
$$

Therefore $\left(S E_{R}\right)$ and $\left(S E_{A}\right)$ become:

$$
\begin{gathered}
S E_{R}=-10 \log (1-R) \\
S E_{A}=-10 \log \left(1-A_{\text {eff }}\right)=-10 \log (T / 1-R)
\end{gathered}
$$

Based on shielding theory, shielding effectiveness (SE) is as follow:

$$
\begin{gathered}
S E_{A}(d B)=20 d\left(\frac{\mu_{r} \omega \sigma}{2}\right)^{1 / 2} \log (e) \\
S E_{R}(d B)=10 \log \left(\frac{\sigma}{16 \mu_{r} \omega \varepsilon_{0}}\right) \\
S E_{\text {total }}(d B)=20 d\left(\frac{\mu_{r} \omega \sigma}{2}\right)^{1 / 2} \log (\theta)+10 \log \left(\frac{\sigma}{16 \mu_{r} \omega \varepsilon_{0}}\right)
\end{gathered}
$$

Where $\mathrm{d}$ is the sample thickness $(\mathrm{cm})$, e is $2.718, \mu_{r}$ is relative magnetic permeability, $\omega=2 \pi f$ is the angular frequency, $\sigma=2 \pi f \varepsilon^{\prime \prime}$ is electrical conductivity $(\mathrm{S} / \mathrm{cm})$ and $\varepsilon_{0}$ is the dielectric constant of vacuum.

\section{Green or Organic Material in Electromagnetic Shielding Application}

For environmental awareness, green or organic materials are the materials of choice for shielding material among a few researchers. In 7 , the authors discussed the reflection loss performance of hexagonal base pyramid microwave absorber using different agricultural waste material. Three sample of agricultural waste are used that is rice husk, rice straw and banana leaves. Microwave absorbers based on dielectric properties of those materials measured with free space measurement technique are designed using Computer Simulation Technology Microwave Studio (CST MWS). The simulation shows that many parameters can affect the performance of an absorber.

Liyana et al. ${ }^{8}$ fabricated microwave absorbers using sugar cane bagasse material. They investigated the potential of sugar cane bagasse as an alternative material for EMI shielding. High carbon contain in agricultural waste particularly sugar cane bagasse increase its ability or potential to be used as absorber material. Besides that, research and experimentation also shows that corn stover could be used as the material for microwave absorber ${ }^{9}$. The preliminary results prove that the performance of the organic absorber is comparable to the commercially available absorber.

Table 1 shows a comparison of reflection loss performance for different type of material as microwave absorber. Agricultural wastes were chosen by many researchers due to their eco-friendly nature, inexpensive, abundantly available and good microwave absorption properties. 
Table 1. Reflection loss performance of different types of materials

\begin{tabular}{|c|c|c|c|}
\hline Researchers & Material & $\begin{array}{c}\text { Target } \\
\text { frequency }\end{array}$ & $\begin{array}{l}\text { Reflection } \\
\text { loss } \\
\text { performance }\end{array}$ \\
\hline $\begin{array}{c}\text { Hassan } \\
\text { Nornikman } \\
\text { et al., } 2011^{10}\end{array}$ & $\begin{array}{l}\text { Rice } \\
\text { husks }\end{array}$ & $7-13 \mathrm{GHz}$ & $\begin{array}{l}\text { Better than - } \\
10 \mathrm{~dB}\end{array}$ \\
\hline $\begin{array}{c}\text { Liyana et al., } \\
2012^{8}\end{array}$ & $\begin{array}{c}\text { Sugar } \\
\text { cane } \\
\text { bagasse }\end{array}$ & $\begin{array}{c}0.1- \\
20 \mathrm{GHz}\end{array}$ & $\begin{array}{l}\text { Better than - } \\
30 \mathrm{~dB}\end{array}$ \\
\hline $\begin{array}{c}\text { H. } \\
\text { Nornikman } \\
\text { et al., } 2010^{7}\end{array}$ & $\begin{array}{c}\text { Rice } \\
\text { husks } \\
\text { Rice } \\
\text { straw } \\
\text { Banana } \\
\text { leaves }\end{array}$ & $1-20 \mathrm{GHz}$ & $\begin{array}{c}\text { Better than - } \\
10 \mathrm{~dB}\end{array}$ \\
\hline $\begin{array}{l}\text { Salleh et al., } \\
2011^{11}\end{array}$ & $\begin{array}{l}\text { Coconut } \\
\text { shell- } \\
\text { derived }\end{array}$ & $8-12 \mathrm{GHz}$ & $\begin{array}{l}\text { Better than - } \\
10 \mathrm{~dB}\end{array}$ \\
\hline $\begin{array}{l}\text { Smythe et } \\
\text { al., } 2014{ }^{9}\end{array}$ & $\begin{array}{l}\text { Corn } \\
\text { stover }\end{array}$ & $\begin{array}{c}5.4- \\
18 \mathrm{GHz}\end{array}$ & \\
\hline $\begin{array}{l}\text { Farhany et } \\
\text { al., } 2012{ }^{12}\end{array}$ & $\begin{array}{c}\text { Dried } \\
\text { banana } \\
\text { leaves }\end{array}$ & $\begin{array}{c}0.1- \\
20 \mathrm{GHz}\end{array}$ & $\begin{array}{c}\text { Average - } \\
82.3 \mathrm{~dB}\end{array}$ \\
\hline $\begin{array}{l}\text { Noordin et } \\
\text { al., } 2012^{13}\end{array}$ & $\begin{array}{l}\text { Oil palm } \\
\text { ash }\end{array}$ & $8-12 \mathrm{GHz}$ & $\begin{array}{l}\text { Better than - } \\
\quad 10 \mathrm{~dB} \\
\text { Best at }-49 \mathrm{~dB}\end{array}$ \\
\hline $\begin{array}{c}\text { Shaaban, Se, } \\
\text { Ibrahim, \& } \\
\text { Ahsan, } 2015 \\
14\end{array}$ & $\begin{array}{l}\text { Rubber } \\
\text { wood } \\
\text { sawdust }\end{array}$ & $1-3 \mathrm{GHz}$ & $\begin{array}{c}\text { Best at - } \\
16.4 \mathrm{~dB}\end{array}$ \\
\hline $\begin{array}{c}\text { Kaur, Aul, \& } \\
\text { Chawla, } \\
2015^{15}\end{array}$ & $\begin{array}{c}\text { Dried } \\
\text { banana } \\
\text { leaves } \\
\text { and coal }\end{array}$ & $8.2-12 \mathrm{GHz}$ & $\begin{array}{c}\text { Average - } \\
45.2 \mathrm{~dB}\end{array}$ \\
\hline
\end{tabular}

\section{Nanocellulose Composites}

Cellulose which is an organic compound easily obtained from nature is a structural component of the cell walls of many plants. It is used mainly for making paper and cardboard but recently it has attracted a lot of interest in various industrial applications ${ }^{16}$. This biopolymer has been used in various application and fields due to its availability, eco-friendly nature, sustainability and also flexibility ${ }^{171816}$.

Cellulose also has received special attention for development of conducting materials. For example, Jabbour et al. ${ }^{19}$ used papermaking techniques to produce graphite/carbon fiber/cellulose fiber composites papers with tuneable conductivity and good mechanical properties. The produced conductive papers are flexible, easy to handle and have an extremely good conductivity. Carbon nanotube (CNT) / cellulose composites material using papermaking process was fabricated in ${ }^{20}$. Higher electric conductivity compared to the usual polymerbased composite materials was achieved without affecting the paper strength.

In recent years, cellulosic fibers in micro and nano scale are gaining attention to replace man-made fibers as reinforcement to make an environment-friendly composite. Researchers worldwide have been focusing on the production of nanocellulose (NC) with crystalline structure because of its exceptional material properties 21.

A few examples of biodegradable polymer-CNF based nanocomposites and their mechanical properties were discussed in ${ }^{17}$. This includes Poly(vinyl alcohol) CNF, Poly(lactic acid) - CNF, Poly(ethylene oxide) CNF, Chitosan - CNF, Starch - CNF and Soy protein $\mathrm{CNF}$. It has been discovered that $\mathrm{NC}$ can be applied to energy devices such as paper batteries, supercapacitors and paper displays.

It has been acknowledged that nanocellulose has great potential as reinforcement in nanocomposites. Therefore nanocelluose can be applied to various applications and fields in the upcoming decades. However, its applicability for electromagnetic shielding notably has not been widely explored. Polymer based composites are still commonly used as electromagnetic interference shielding materials ${ }^{1}$. Additionally, it has been discovered that cellulose are used for conducting material which is very efficient in electromagnetic shielding. High carbon content also increases its ability to be used for electromagnetic shielding. Besides, different types of filler could be incorporated into nanocellulose composite in order to get a better and higher performance of electromagnetic shielding. For example graphene, carbon nanotube (CNT), Carbon Black (CB) and other C-based materials ${ }^{22}$. Therefore, nanocellulose composite has a high potential to be develop as an alternative material for electromagnetic shielding that is lightweight and with a wider bandwidth. 


\section{Conclusion}

The recent development of green material in electromagnetic shielding and nanocellulose composite were reviewed. It has been show that nanocellulose has an exciting potential as reinforcement in nanocomposites and are indeed the future materials. Nanocellulose can be applied to various applications and fields. Further studies and researches on nanocellulose as alternative material to replace current petroleum based material are highly required especially in electromagnetics shielding applications.

\section{Acknowledgement}

This research was funded by the grant of Fundamental Research Grant Scheme (No. 9003-00591) under Ministry of Education, Malaysia.

\section{References}

1. Thomassin, J. M. et al. Polymer/carbon based composites as electromagnetic interference (EMI) shielding materials. Mater. Sci. Eng. $R$ Reports 74, 211-232 (2013).

2. Suchea, M. et al. Nanostructured composite layers for electromagnetic shielding in the $\mathrm{GHz}$ frequency range. Appl. Surf. Sci. 352, 151-154 (2015).

3. Chung, D. D. . Electromagnetic interference shielding effectiveness of carbon materials. Carbon N. Y. 39, 279-285 (2001).

4. Al-Saleh, M. H. \& Sundararaj, U. Electromagnetic interference shielding mechanisms of $\mathrm{CNT} /$ polymer composites. Carbon N. Y. 47, 1738-1746 (2009).

5. Bayat, M., Yang, H., Ko, F. K., Michelson, D. \& Mei, A. Electromagnetic interference shielding effectiveness of hybrid multifunctional Fe3O4/carbon nanofiber composite. Polym. (United Kingdom) 55, 936-943 (2014).

6. Kuester, S., Barra, G. M. O., Ferreira, J. C., Soares, B. G. \& Demarquette, N. R. Electromagnetic interference shielding and electrical properties of nanocomposites based on poly (styrene-b-ethylene-ran-butylene-b-styrene) and carbon nanotubes. Eur. Polym. J. 77, 43-53 (2016).

7. Nornikman, H., Malek, F., Soh, P. J. \& Azremi, A. A. H. Reflection loss performance of hexagonal base pyramid microwave absorber using different agricultural waste material. 2010 Loughbrgh. Antennas Propag. Conf. LAPC 2010 313-316

(2010). doi:10.1109/LAPC.2010.5666029

8. Liyana, Z. et al. Investigation of sugar cane bagasse as alternative material for pyramidal microwave absorber design. IEEE Symp. Wirel. Technol. Appl. ISWTA 66-70 (2012). doi:10.1109/ISWTA.2012.6373879
9. Smythe, B., Casserly, S. \& Arakaki, D. Organicbased microwave frequency absorbers using corn stover. IEEE Antennas Propag. Soc. AP-S Int. Symp. 920-921 (2014). doi:10.1109/APS.2014.6904788

10. Nornikman, H. et al. Setup and Results of Pyramidal Microwave Absorbers Using Rice Husks. Prog. Electromagn. Res. 111, 141-161 (2011).

11. Salleh, M. K. M. et al. Experimental verification of multi-layer coconut shell-derived microwave absorbers. 2011 IEEE Int. RF Microw. Conf. RFM 2011 - Proc. 115-118 (2011). doi:10.1109/RFM.2011.6168709

12. Farhany, Z. S. et al. Potential of dried banana leaves for pyramidal microwave absorber design. IEEE Symp. Wirel. Technol. Appl. ISWTA 60-65 (2012). doi:10.1109/ISWTA.2012.6373878

13. Noordin, I. R. M. et al. Investigation of oil palm ash microwave absorber for broadband application. Proc. - 2012 IEEE 8th Int. Colloq. Signal Process. Its Appl. CSPA 2012 232-235 (2012). doi:10.1109/CSPA.2012.6194724

14. Shaaban, A., Se, S., Ibrahim, I. M. \& Ahsan, Q. Preparation of rubber wood sawdust-based activated carbon and its use as a filler of polyurethane matrix composites for microwave absorption. New Carbon Mater. 30, 167-175 (2015).

15. Kaur, R., Aul, G. D. \& Chawla, V. Improved Reflection Loss Performance of Dried Banana Leaves Pyramidal Microwave Absorbers by Coal for Application in Anechoic Chambers. 43, 157164 (2015).

16. Potulski, D. C., De Muniz, G. I. B., Klock, U. \& De Andrade, A. S. Influ??ncia da incorpora????o de celulose microfibrilada nas propriedades de resist??ncia mec??nicas do papel. Sci. For. Sci. 40, 345-351 (2014).

17. Kim, J. H. et al. Review of nanocellulose for sustainable future materials. Int. J. Precis. Eng. Manuf. - Green Technol. 2, 197-213 (2015).

18. Pandey, J. K., Takagi, H., Nakagaito, A. N., Saini, D. R. \& Ahn, S. H. An overview on the cellulose based conducting composites. Compos. Part B Eng. 43, 2822-2826 (2012).

19. Jabbour, L., Chaussy, D., Eyraud, B. \& Beneventi, D. Highly conductive graphite/carbon fiber/cellulose composite papers. Compos. Sci. Technol. 72, 616-623 (2012).

20. Imai, M., Akiyama, K., Tanaka, T. \& Sano, E. Highly strong and conductive carbon nanotube/cellulose composite paper. Compos. Sci. Technol. 70, 1564-1570 (2010).

21. Jung, Y. H. et al. High-performance green flexible electronics based on biodegradable cellulose nanofibril paper. Nat. Commun. 6, 7170 (2015).

22. Qin, F. \& Brosseau, C. A review and analysis of microwave absorption in polymer composites filled with carbonaceous particles APPLIED PHYSICS REVIEWS A review and analysis of 
microwave absorption in polymer composites

filled with carbonaceous particles. 61301, (2012). 